\title{
Arte e técnica a serviço do conhecimento: as ilustrações científicas
}

\section{Art and technique at the service of knowledge: the scientific illustrations}

\author{
Aline Lopes de Lacerda \\ Chefe do Serviço de Arquivo Histórico, Departamento de Arquivo e Documentação/Casa de Oswaldo Cruz/Fiocruz. \\ lacerda@fiocruz.br
}

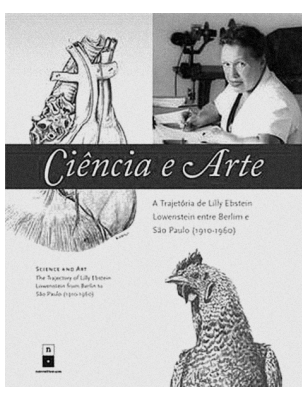

CYTRYNOWICZ, Monica Musatti; CYTRYNOWICZ, Roney. Ciência e arte: a trajetória de Lilly Ebstein Lowenstein entre Berlim e São Paulo (1910-1960). São Paulo: Narrativa Um. 2013. 238p.

Dara uma abordagem reflexiva sobre os usos e funções de ilustrações 1 nas atividades científicas, podem ser adotadas diversas perspectivas de análise. A mesma pluralidade de enfoques está presente nos estudos sobre o desenvolvimento do papel da representação figurativa como dispositivo didático na trajetória da ciência como campo de conhecimento.

É possível, por exemplo, investigar essa rica relação na perspectiva da avaliação do papel das imagens na produção e divulgação do conhecimento. Imagens tanto produzidas manualmente quanto provenientes dos principais dispositivos técnicos de representação visual disponíveis, principalmente a partir do século XIX. Em um passo adiante, é possível estudar a própria constituição de uma forma mediadora de alcance do conhecimento da ciência na sua dimensão propriamente visual, que se tornará permanente e irremediavelmente associada ao trabalho científico. Assim, as interconexões entre a escrita científica e as ilustrações que a acompanham são debatidas por linhas de estudos que discutem as dimensões artísticas, pedagógicas, de popularização e difusão do conhecimento científico conjugadas no exercício de ilustrar por meio de imagens. As funções das ilustrações parecem ser tema que gravita em torno dessas discussões (Fabris, Kern, 2006).

É possível também abordar as conexões entre ciência e arte numa perspectiva de desenvolvimento institucional do ofício do desenhista ou ilustrador científico. No caso do Brasil, o foco incidiria sobre a institucionalização da ciência no país, principalmente na última metade do século XIX e, sobretudo, durante o século XX, quando são formados e consolidados institucionalmente centros importantes de produção científica em várias áreas. Nesse processo, as práticas científicas são também desenvolvidas de forma a dotar os trabalhos do rigor e da excelência pretendidos. Certos ofícios são requeridos como peças fundamentais ao desenvolvimento dos próprios trabalhos científicos nos seus cenários principais laboratórios e trabalhos em campo - e, fundamentalmente, para compor o discurso científico 
a ser registrado, traduzido figurativamente, utilizado como prova, divulgado, ensinado e, finalmente, arquivado. Todas essas funções estão embutidas na valorização, nos espaços edificados para o trabalho científico, na existência de setores de desenho, fotografia, cartografia e de profissionais habilitados para exercer a função de "tradutores" entre linguagens distintas.

E é igualmente possível refletir sobre o tema das ilustrações científicas a partir da reconstituição analítica de uma trajetória individual, cujo ator foi peça importante em sua área de atuação, com projeção e reconhecimento entre os pares e que tenha desenvolvido um trabalho constante, alinhado às questões maiores - institucionais, profissionais, estéticas, técnicas que constituem o contexto do modo de exercer o ofício no seu tempo.

O livro Ciência e arte: a trajetória de Lilly Ebstein Lowenstein entre Berlim e São Paulo (1910-1960), de Monica Musatti Cytrynowicz e Roney Cytrynowicz, parte desta última forma de abordagem, mas articula elementos analíticos das três possíveis abordagens apresentadas acima. Tendo como mola propulsora o desejo da neta de Lilly Ebstein Lowenstein - e guardiã de sua memória - de reconstruir a trajetória da avó, o livro serve de veículo para o acionamento da lembrança no âmbito familiar e a transformação dessa lembrança em memória compartilhada por meio de pesquisa e análise dos registros que dão suporte empírico à narrativa analítica presente na obra.

No caso de Lilly, a essas dimensões das relações entre imagem e conhecimento científico que seu trabalho oferece como fonte vêm se somar aspectos singulares de sua trajetória. Imigrante alemã que chega ao Brasil em 1925, formou-se, ainda em Berlim, em escola para moças que oferecia estudo técnico e científico no campo do desenho, da fotografia e das técnicas operacionais envolvendo essas áreas. Ao mesmo tempo mulher, imigrante e portando as credenciais necessárias para atuar profissionalmente no campo da ilustração científica, se insere como profissional em instituições científicas renomadas no Brasil e conquista uma carreira reconhecida num espaço profissional predominantemente masculino. Nas palavras dos autores na introdução do livro,

a trajetória de Lilly Ebstein Lowenstein pode ser narrada sob várias perspectivas que se integram e se entrelaçam. A primeira delas é a de uma vida que sintetiza o percurso das mulheres nas primeiras décadas do século 20, período de consolidação da emancipação e do acesso ao estudo e às profissões técnicas em países como a Alemanha, onde Lilly realizou a sua formação ... A trajetória de Lilly é também a de uma mulher profissional, entre a ciência e a arte, que se lançou à imigração no Novo Mundo e conquistou um lugar de reconhecimento social, profissional e intelectual ... É também uma trajetória no mundo da ciência e da pesquisa científica (p.11).

Fartamente ilustrado, como era de esperar, o livro não se atém apenas à exploração dos desenhos e ilustrações produzidos por Lilly - todos de técnica e estética impecáveis e articula bem diversos tipos de fontes provenientes de ampla pesquisa documental. Todos os registros transformados, por sua vez, em imagens que integram uma boa narrativa visual que, em paralelo ao texto escrito, contribui para dar forma ao todo, ao objetivo do livro, o de oferecer múltiplos caminhos de observação dessa trajetória permeada pela interpenetração de aspectos tão singulares.

Partindo de dois documentos pessoais da desenhista - sua certidão de nascimento e seu boletim escolar - a pesquisa documental articula registros provenientes de diversos locais 
que Lilly percorreu, num movimento de construção narrativa biográfica multifacetada do ponto de vista da exploração das fontes, o que é um ponto alto do livro.

O leitor acompanha os primeiros estudos de sua formação técnica, ainda na década de 1910, numa escola em Berlim que investe na formação sistematizada dos "fotomicrógrafos". No capítulo dedicado à formação de Lilly na Escola Lette-Verein ficam evidentes as conexões do olhar instrumental valorizado pelo domínio dos novos dispositivos técnicos de captação de imagens - e a fotografia é o centro desse universo no período - com a área da medicina. Não bastava o domínio técnico de obtenção da imagem, era esperado também o entendimento mais profundo, pelo operador, do objeto a ser representado. Um pré-requisito na formação técnica era o conhecimento nas áreas biomédica e botânica para que o ilustrador científico entendesse o objeto que estivesse retratando. Em consequência, durante a sua formação na Alemanha, a desenhista é obrigada a conhecer anatomia, por exemplo, o que a torna representante de uma formação técnica com forte embasamento científico, aspecto que se reflete em seu trabalho. O livro explora bem o preparo e a formação pelas quais Lilly passou para ter destreza no ofício de fotomicrografia. As técnicas para a elaboração dos registros visuais variavam, passando por colorização manual de fotos, por produção de desenhos a partir de fotos etc. Era necessário, ainda, ter um domínio técnico sobre o uso de lentes, de revelação, bem como de formatos e suportes fotográficos.

Sua vinda para o Brasil e seu ingresso na Faculdade de Medicina e Cirurgia de São Paulo em 1926 - onde em pouco tempo se projeta como a principal desenhista e fotomicrógrafa ocorrem num contexto de transformação do próprio campo científico, consubstanciado no incremento de pesquisas básicas, de atividades em laboratório, preconizados por uma medicina experimental. Esse contexto de desenvolvimento dos trabalhos científicos em outras bases metodológicas confere valor ao desenho científico como atividade integrante da estrutura operacional das instituições de ciência. Segundo os autores do livro, na Faculdade de Medicina e Cirurgia de São Paulo o desenho científico ganha novo status pelas publicações, nas quais servia a diversas cadeiras da faculdade, como anatomia descritiva e topográfica, anatomia patológica (parasitologia, microbiologia, embriologia, histologia, técnica cirúrgica, clínica cirúrgica etc.). Havia igualmente demanda por ilustrações nas teses defendidas.

Alguns detalhes ajudam a entender o processo de profissionalização de Lilly. O uso de créditos nos trabalhos é um deles. No período, era comum a ausência de créditos nas ilustrações. Em muitos casos, os próprios professores ou cientistas ilustravam seus trabalhos. Para os autores do livro, a presença de créditos nos trabalhos de Lilly, mesmo considerando a existência de trabalhos seus sem assinatura, é um indício de reconhecimento do desenho científico como atividade autônoma, conferindo a esse trabalho estatuto científico e profissional.

O trabalho se vale de pesquisa bastante minuciosa e ao mesmo tempo abrangente em termos de escolha de fontes e uso das informações obtidas. Por exemplo, os autores recorrem ao levantamento, no Diário Oficial da União, dos proventos recebidos nos cargos ocupados por Lilly no período - no caso, desenhista micrógrafo - para, numa análise comparativa com outros cargos na mesma instituição, inclusive de direção, aferir a importância da atividade pela remuneração a ela conferida (que era alta à época!).

Em relação às funções mais gerais atribuídas às ilustrações científicas, o livro levanta aspectos interessantes. Um deles é a centralidade que a imagem técnica assume como veículo 
dos registros, por se apresentar como um discurso visual mais objetivado, nos trabalhos científicos em todas as áreas. A fotografia, nesse sentido, considerada a reprodução exata e fidedigna do modelo, abre caminhos de descrição, de registro e de arquivamento bastante úteis ao método científico (Fabris, 2002, p.33). Mas e o papel do desenho nesse processo? Muito antes do advento das imagens técnicas, ele era o principal meio de representação. Se, por um lado, a representação claramente mediada pela mão humana se vê objeto de críticas na comparação com as novas formas de representação objetivas, por outro, nas ilustrações científicas, é ainda o desenho que desempenha determinados papéis didáticos e de divulgação de difícil transferência às fotografias, como o livro demonstra.

É interessante observar que a busca do "realismo instrumental" (Fabris, 2002, p.39), que impulsiona o uso das imagens fotográficas nos trabalhos científicos, não se impõe como conduta absoluta, uma vez em que nem sempre o "efeito de real" fazia face à performance requerida da representação visual nos inúmeros trabalhos desenvolvidos. Em algumas funções, as linhas dos desenhos foram facilmente substituídas por essas imagens mais realistas obtidas por contrastes de luz. Esse é o caso das imagens microscópicas que inauguraram a possibilidade de acesso ao que era imperceptível à visão humana ao mesmo tempo em que propiciavam o registro para o trabalho descritivo e analítico a partir dos elementos constitutivos do objeto retratado tornados realidade visualmente observável. Segundo Frizot (1998, p.276-277), “o progresso científico alcançado dependia não apenas do acesso ao invisível como também da transcrição do que foi feito visível opticamente - em termos de forma, diferença de material, limitações de substância - e sobre a explicação dessas diferenças". Ao reter as qualidades do original, o registro fotográfico permitia a sua revisão e reinterpretação, funções caras ao métier científico.

Já o desenho, segundo Correia (2011), mantém algumas vantagens sobre as fotografias, principalmente nas funções didáticas - explicativas, de síntese ou de guia -, a partir da imagem de um objeto ou fenômeno cujo conhecimento se pretende transmitir. O objetivo da ilustração científica, notadamente do desenho, seria representar tipificando o objeto ou fenômeno, o "elucidativo/representativo" do objeto em causa, com vistas a facilitar o seu reconhecimento (Correia, 2011, p.228). Essa performance específica atingida pela ilustração manual fica evidente nas palavras do Dr. Mario Marco Napoli, professor emérito da Faculdade de Medicina da USP e ali estudante entre 1941 e 1946, citado em depoimento no livro, "o desenho tem a vantagem de documentar com pormenores que interessam e era bem mais real do que a fotografia, que não atingia esse resultado. ... O que vale na medicina é a documentação. Por mais que a gente descreva, nunca é como o desenho, que fala, demonstra" (p.105).

Especificidades à parte, desenhos e fotografias se uniam na busca pela construção do discurso científico num processo que também alimentava a articulação discursiva desses dispositivos como arquivos da ciência. No caso em questão, as ilustrações, segundo os autores do livro, seriam, portanto, "parte importante do projeto de consolidação do ensino na Faculdade de Medicina, já que as imagens sistematizavam as práticas e permitiam a sua reprodução com exata precisão, seja para a identificação de uma doença, seu diagnóstico, seja seu tratamento, sejam as cirurgias, o que era ensinado em aulas práticas nas quais os alunos observavam e participavam e, principalmente, nas pesquisas" (p.74). 
Acompanhando a linha cronológica do livro, em 1934 a Faculdade de Medicina e Cirurgia de São Paulo passa a fazer parte da Universidade de São Paulo, e, nesse processo, Lilly torna-se então funcionária da universidade. Nessa mesma época naturaliza-se brasileira. Em 1944 passa a colaborar profissionalmente para o Hospital das Clínicas, associado à Faculdade de Medicina. Torna-se chefe do Departamento de Desenho e Fotografia e ministra cursos preparatórios de assistentes de documentação científica em desenho e fotografia, num movimento de formação de mão de obra para o ofício. Envolve-se na atividade de ilustração de anatomia com o Dr. Alfonso Bovero, responsável pela cátedra de Anatomia na Faculdade de Medicina, passando a produzir trabalhos de ilustração para as pesquisas de Bovero, bem como de muitos de seus discípulos, utilizando o desenho e a fotomicrografia.

A partir da década de 1930, Lilly passa a colaborar com o Instituto Biológico de São Paulo, fundado em 1927 com vistas ao combate à broca do café. Tendo como primeiro diretor Arthur Neiva, o instituto passa a ter Lilly como ilustradora atuante para a sua seção de anatomia patológica, vinculada à Divisão Animal do instituto. Essa fase foi marcada sobretudo pela parceria que Lilly estabelece com o médico e pesquisador José Reis, atuante nos estudos da ornitopatologia. A função das ilustrações produzidas nesse trabalho era integrar folhetos impressos para distribuição a produtores rurais, com o objetivo de ilustrar procedimentos no trato com o controle de doenças na criação de animais. Nesse veículo científico encontravam-se conjugados os aspectos de "divulgação" de conhecimento acumulado nas pesquisas médicas do instituto; de "veículo pedagógico", posto que os folhetos visavam informar o melhor procedimento e ensinar a sua reprodução no trato com os animais (desde a forma de criação dos animais, passando pela identificação dos sintomas das doenças, até a conduta a ser seguida no tratamento); e de "veículo de popularização" do conhecimento científico, uma vez que eram construídos esquemas, tanto de detecção de doenças quanto de formas de seu tratamento. Os desenhos cumpriam a função de descrever visualmente os métodos a seguir observando um público heterogêneo de criadores de animais, complementando a descrição textual com detalhes descritivos só possíveis de ser apreendidos por meio da narrativa visual. Interessante pensar na presença de um ideal de receptor para as ilustrações, orientando o desenhista na construção da representação visual a ser veiculada nos diferentes tipos de publicações, seja ela para públicos especializados, seja para públicos mais amplos. Sobre essa questão, a da consciência de um tipo de público a que se destina a publicação na própria idealização e produção do registro visual pelo artista, é interessante citarmos o trabalho de Oliveira e Conduru (2004. p.336-338), no qual afirmam que o uso cognitivo da imagem é sempre ligado à ideia de um leitor, de um perfil de consumidor da informação visualmente registrada. Todo um aparato sintático é articulado no sentido de produzir um discurso visual com objetivo claro: a representação deve manter com o referente uma relação de verossimilhança e, ao mesmo tempo, abordá-lo do ponto de vista de quem quer explicar mostrando. As formas figurativas podem ser variadas, mas a sua função nos trabalhos científicos é sempre caracterizar o objeto, restringindo as possibilidades de interpretações subjetivas num discurso que se pretende objetivado.

Lilly se aposenta em 1955, completando 29 anos de atividade na Universidade de São Paulo. Seu último e grande trabalho é o livro de anatomia topográfica de Odorico Machado 
de Souza, anatomista e professor da Faculdade de Medicina, intitulado Anatomia topográfica. Parte Especial. Membro Superior, de 1956. Os originais que serviram a essa publicação hoje estão reunidos em um álbum e, segundo os autores, se "constitui [n]o mais completo conjunto de desenhos originais de Medicina realizados por Lilly (p.155). Ainda segundo os autores, trata-se de um trabalho clássico de desenho de anatomia que se insere na tradição histórica de desenhos desse tipo produzidos desde 1543 pelo famoso anatomista Andreas Vesalius.

O livro dedica o último capítulo à discussão sobre o uso da fotomicrografia nos trabalhos científicos, técnica fotográfica de obtenção de imagens ampliadas que permite o registro das imagens captadas pelo microscópio. Seu uso nos trabalhos científicos significou a possibilidade de observação de detalhes de estruturas invisíveis à observação visual humana, tais como células e micróbios. Assim, um inventário visual de tecidos, culturas, peças anatômicas e outros elementos do trabalho científico era produzido graças à presença da fotografia nas etapas do trabalho científico, forjando uma nova fonte de demonstração de aspectos morfológicos desses elementos biológicos. Os autores do livro observam que a fotomicrografia torna-se peça central no estudo da bacteriologia, principalmente com os trabalhos de Robert Koch. Como já apontado, um aspecto marcante introduzido pelo uso sistemático de registros visuais com capacidade de reprodução e que vai ter impacto na própria dinâmica do trabalho científico é a incorporação da técnica fotográfica como instrumento tanto de registro dos processos de visualização demandados pelas próprias pesquisas quanto de documentação das etapas das atividades de trabalho, visando ao arquivamento e função de prova dos conhecimentos gerados pelos estudos, além da função propriamente ilustrativa e descritiva das imagens.

Por todos esses aspectos, e pelo prazer visual que o livro proporciona, é leitura recomendada aos que se interessam pelo desenvolvimento da atividade científica no Brasil, bem como aos que apreciam análises sobre as funções das representações visuais para campos profissionais específicos - numa linha de investigação histórica sobre os usos sociais de dispositivos de registro visual como a fotografia e o desenho, por exemplo.

\section{REFERÊNCIAS}

CORREIA, Fernando.

A ilustração científica: "santuário" onde a arte e a ciência comungam. Visualidades, v.9, n.2, p.221239. 2011.

FABRIS, Annateresa.

Atestados de presença: a fotografia como instrumento científico. Locus, v.8, n.1, p.29-40. 2002.

FABRIS, Annateresa; KERN, Maria Lúcia Bastos (Org.).

Imagem e conhecimento. São Paulo: Editora da Universidade de São Paulo. 2006.
FRIZOT, Michel (Ed.).

A new history of photography. Köln: Könemann Verlagsgesellschaft. 1998.

OLIVEIRA, Ricardo Lourenço de; CONDURU, Roberto.

Nas frestas entre a ciência e a arte: uma série de ilustrações de barbeiros do Instituto Oswaldo Cruz. História, Ciências, Saúde - Manguinhos, v.11, n.2, p.335-84. 2004. 